\title{
The Impact of Climate Change on Rice Production Center at Area of the City near the Beach in Indonesia
}

\author{
Joko Wiratmo', Yuyun Yuwariyah ${ }^{2}$, Ruminta $^{3}$, Yayat Rochayat Suradinata ${ }^{4}$ \\ ${ }^{1}$ Study Program of Meteorology, Faculty of Earth Science and Technology, Bandung Institute of Technology \\ ${ }^{2}$ Graduate Program of Agriculture, Faculty of Agriculture, University of Padjadjaran \\ ${ }^{3}$ Graduate Program of Agriculture, Faculty of Agriculture, University of Padjadjaran \\ ${ }^{4}$ Graduate Program of Agriculture, Faculty of Agriculture, University of Padjadjaran
}

\begin{abstract}
Impacts of climate change in the region of the northern coast of West Java in particular Karawang investigated using climate data, agricultural systems data, and socio-economic communities data. Given the comprehensiveness of climate data are hard to obtained data then the IPCC (Intergovernmental Panel on Climate Change) are used for this research. The data system of agriculture and social economy community Karawang data obtained from BPS (Central Bureau of Statistics). The results show that the eleven subdistricts in the region have a level of vulnerability, hazard and risk. Among the 11 subdistrict, subdistrict of Tempuran hazard level is high, very high levels of vulnerability and risk levels of the farm system. Sub-district level hazard of Pedes is high while the Banyusari had a very high level of vulnerability. Therefore then the forward should be attempted so that the impacts of climate change on farming systems in the coastal town of Karawang district must be slowed to avoid a severe impact on the production of rice.
\end{abstract}

Keywords: Climate change, Vulnerability, Risk, Farming systems.

\section{Introduction}

Climate change has brought important impacts for all sectors of life, agricultural sector is no exception. There have been many reported from various parts of the world that shows that the agricultural sector has a particular vulnerability levels (Lee et al., 2012; Knox et al., 2012; Osborne and Wheller, 2013; Joseph and Francisco, 2009; Sultan, 2012). Agricultural production in various parts of the world show that the impacts of climate change is quite significant. Happens a decrease in agricultural production from a few percent to over ten percent (Knox et al.,2012 ). Indonesia is located in the tropics the Equator that are vulnerable to climate change. Even according to Measey (2010) the level of vulnerability of farming systems in the region are grouped into high scale. If so then it is possible that in the future the vulnerability levels will be higher and disrupted farming systems in the region. As one of the world's rice producers in 2012 who contributed amounted to $11 \%$ (chinawaterrisk.org) then the distractions on his farm system could have an impact is not good for the people of Indonesia. Most of the region is a region near the coast are also affected by an increase in the sea level due to the melting of polar ice caps. As one of the regions bordering the Java Sea then Karawang farm production could be affected. The city is included in the West Java province who donate rice production $12.35 \%$ of West Java and $2.2 \%$ of the national rice production (BPS, 2014). The city has 30 subdistrict which is mostly designated as areas of rice production, even being kept to the existence of local regulations prohibiting their citizens to change his farmland into non agricultural land. Climate change is happening as long as it can bring the impact of unfavourable for agricultural sector of this region in the future. The risk of a decline in agricultural production, especially rice could have an impact on the availability of staple foodstuffs and food security in the region. The purpose of this research is to know the extent of the level of risk experienced by the agricultural system of rice plant in the coastal city.

\section{Material and Method}

To find out how big the risk levels of the farm system of rice plant in the future then the required climate data, agriculture and social economy data. Climate data in the form of monthly temperature and rainfall. Given that BMKG (Agency for meteorology, Climatology and Geophysics) has no observers in Karawang station then temperature data is represented by the region adjacent to the area of research i.e. station observers in the Regency of Subang, a town in the East of Karawang. Monthly rainfall data obtained from the Department of Agriculture of Karawang. Good projection data of temperature or precipitation and sea level rise for the year 2030 prepared fromdatahttp://www.ipcc-data.org/auto/ar4/var-

air_temperatureand http://www.ipcc-data.org/auto/ar4/varair_precipitationusing linear regression. The data includes agricultural land area data on drought and flooding, extensive farmland, agricultural lands, topography, irrigation infrastructure and socio-economic data covering whilst the number of farmers, farmersincome, level of education of farmers and the agricultural share in GDP (Gross Domestic Income). The Subdistricts reviewed were Telukjambebarat, Telukjambetimur, Banyusari, Telagasari, Rawamerta, Kutawaluya, Tempuran, Pedes, Tirtajaya, on Batujaya, and Pakisjaya. The data obtained from the BPS and the Department of agriculture for the period of Karawang 2004 up to 2013. To know the projection of the level of risk then do some stage determination i.e. determination of hazard, vulnerability and risk itself. To 


\section{International Journal of Science and Research (IJSR) \\ ISSN (Online): 2319-7064 \\ Index Copernicus Value (2013): 6.14 | Impact Factor (2015): 6.391}

determine the weight of each component in determining the level of risk is then done by involving opinion from several parties i.e. from colleges, research institutes and non- governmental organization (NGO) using the method of pairwisecomparison (Bachtiaret al., 2013).

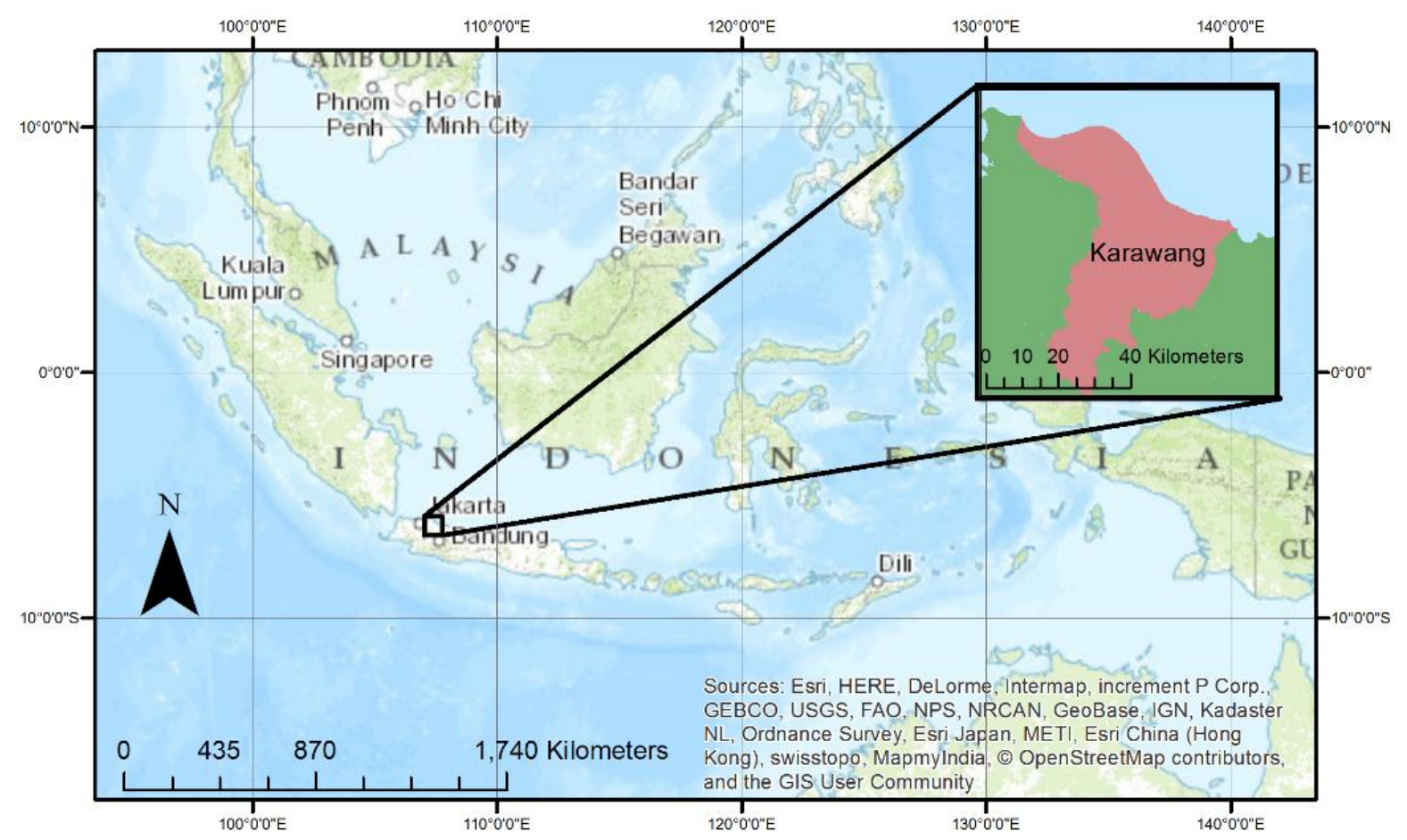

Figure 1: Location of the study where the Karawang located slightly to the East of Jakarta, the capital of Indonesia

\subsection{Hazard}

Hazard determination form of decreased productivity, land area and area harvest rice crops is done using the main input of temperature and precipitation. The influence of temperature and rainfall against a decrease in crop productivity can be written as follows:

$$
\Delta Y_{a}=\max \left(\Delta Y_{p 1}, \Delta Y_{p 2}, \Delta Y_{p 3}\right)
$$

Where

$\Delta Y_{a}$ is decrease in the productivity of the rice plant due to an increase in air temperature and precipitation (ton/ha)

$\Delta Y_{p 1}$ ispotential decrease in productivity of rice due to the respiration of plants (tonnes/ha)

$\Delta Y_{p 2}$ is potential decrease in productivity of rice due to the age of the plants (tonnes/ha)

$\Delta Y_{p 3}$ is potential decrease in paddy productivity (ton/ha) due to thedrought flood and drought affect vast harvest rice crops while the increase sea level affect the broad decline in farmland.

\subsection{Vulnerability}

The vulnerability of agriculture to climate change system can be examined from three components namely the exposure (E), sensitivity (S), and the adaptive capacity (AC). The magnitude of the vulnerability to climate change in the area of Karawang is very dependent on the magnitude of the weighting of the three components, which are formulated as follows:

$$
V=(E x S) / A C
$$

Where

$\mathrm{V}$ is the vulnerability

$\mathrm{E}$ is the exposure

$\mathrm{S}$ is the sensitivity

Adaptive capacity is the capacity or ability to adapt. Some of the indicators used to determine the level of exposure, sensitivity, and adaptability shown in the Figure 2.

\subsection{Risk}

Calculation of the projection system of agriculture risk from climate change in the area of Karawang calculated using the following equation:

Where

$$
R=H \times V
$$

$\mathrm{R}$ is the Risk

$\mathrm{H}$ is the Hazard calculated from the decline in agricultural production

$\mathrm{V}$ is the Vulnerability

The definition of hazard, vulnerability, risk and others follow the definition stated by IPCC (IPCC, 2001). Risk (R) of Karawang Regency in eleven subdistricts further spatial mapped using GIS (Geographic Information System) and its analyzing reinforced with the study of literature. 


\section{International Journal of Science and Research (IJSR) \\ ISSN (Online): 2319-7064}

Index Copernicus Value (2013): 6.14 | Impact Factor (2015): 6.391

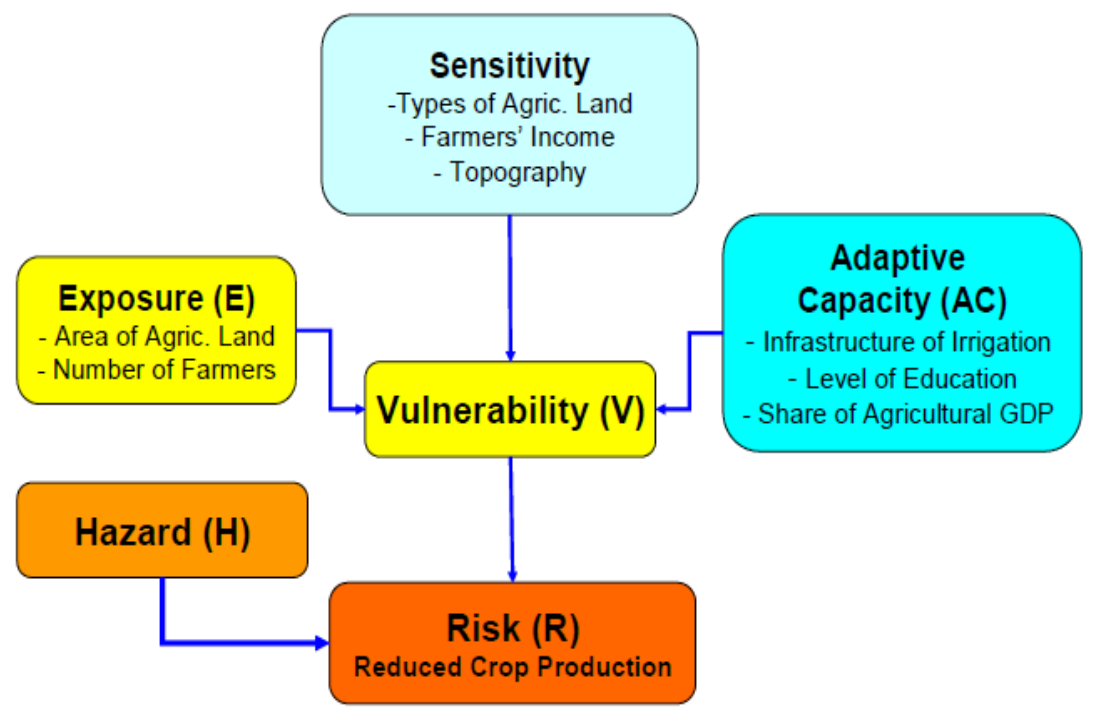

Figure 2:Flowchart hazard potential, vulnerabilities and risks of climate change on rice production (Ruminta and Handoko, 2012)

\section{Results and discussions}

The results show that the eleventh Karawang Regency in level hazards, vulnerability and risks of different farming systems. Hazard level as shown in Figure 3 shows that subdistrictsof Pedes and Tempuran have value most highly. This means that both the subdistrict has a very high level of hazard. Other subdistricts show value of hazard from very low to high. The high value of the hazard that threatens the farming systems on both the sub district affected by the magnitude of the components of the temperature, rainfall, floods and droughts and rising sea levels. Rising sea levels will submerge the two districts covering an area of 2190.02 hectares and 2026.88 hectares. Forecasted in the future after the era of 2030 sea level rise more this will be more and more affects the extent of agricultural land in the town near the coast like Karawang. Sea-level rise according to the SRES A1B scenario is amounting to 0.35 metres per ten years.

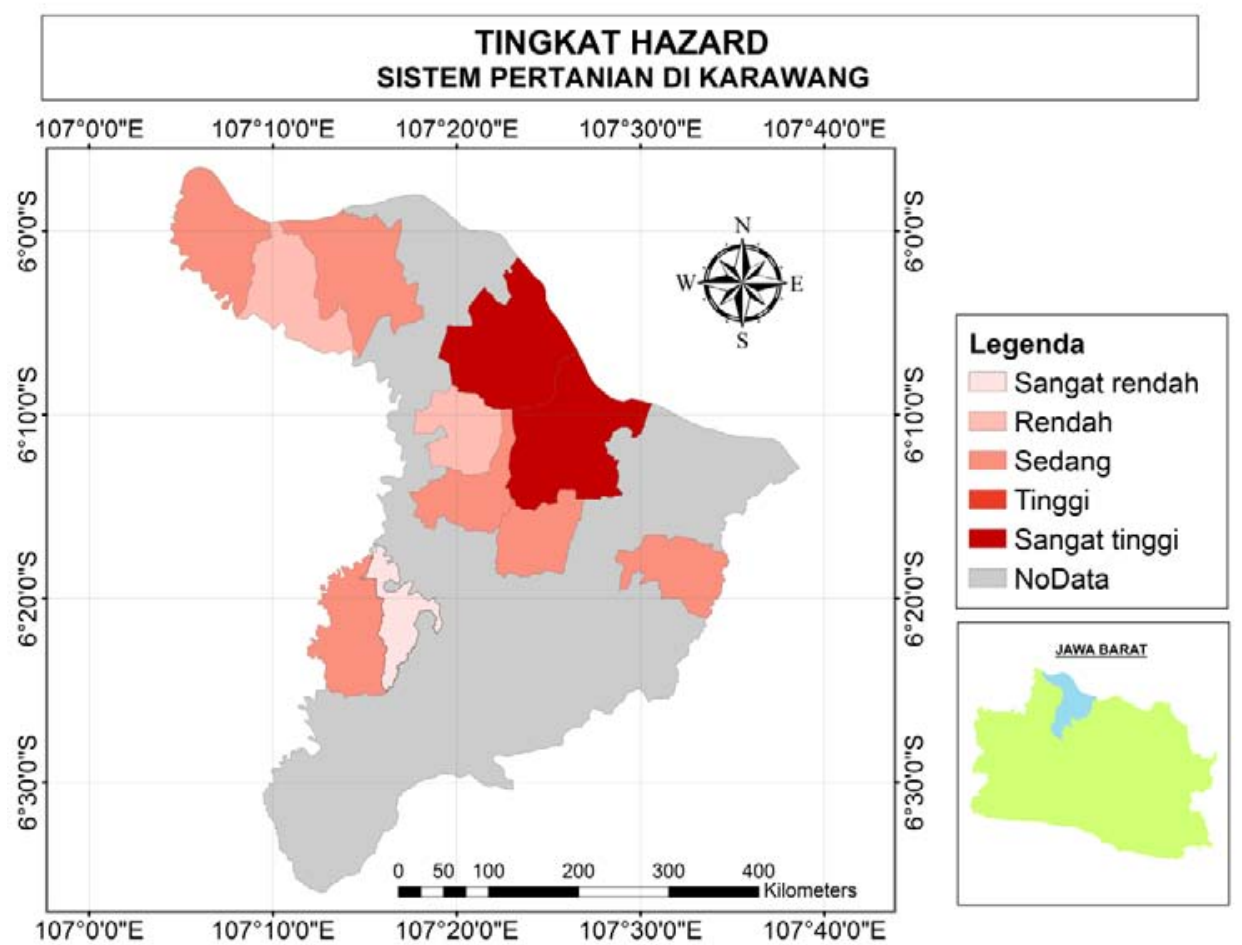

Figure 3:The level of hazard experienced agricultural system in Karawang which showed that subdistrictsTempuran and Pedes had the highest value

The level of vulnerability of agricultural systems is determined by the values of exposure, sensitivity and adaptability. As well as on the degree of hazard, vulnerability in the region also varies. It is interesting that subdistrictPedes no longer has the highest level however has shifted to high level decreased to its vulnerability. The 


\section{International Journal of Science and Research (IJSR) \\ ISSN (Online): 2319-7064 \\ Index Copernicus Value (2013): 6.14 | Impact Factor (2015): 6.391}

very high vulnerability subdistrict in Figure 4 is Tempuran and Banyusari. Sub district of Banyusari compared with Tempuranhave a little higher level of vulnerability. Considering the variation of each value exposure, sensitivity and adaptability to each subdistrict so a bit difficult to say why Tempuran and Banyusari have a very high level of vulnerability. This mean that it is needed to be further investigated.

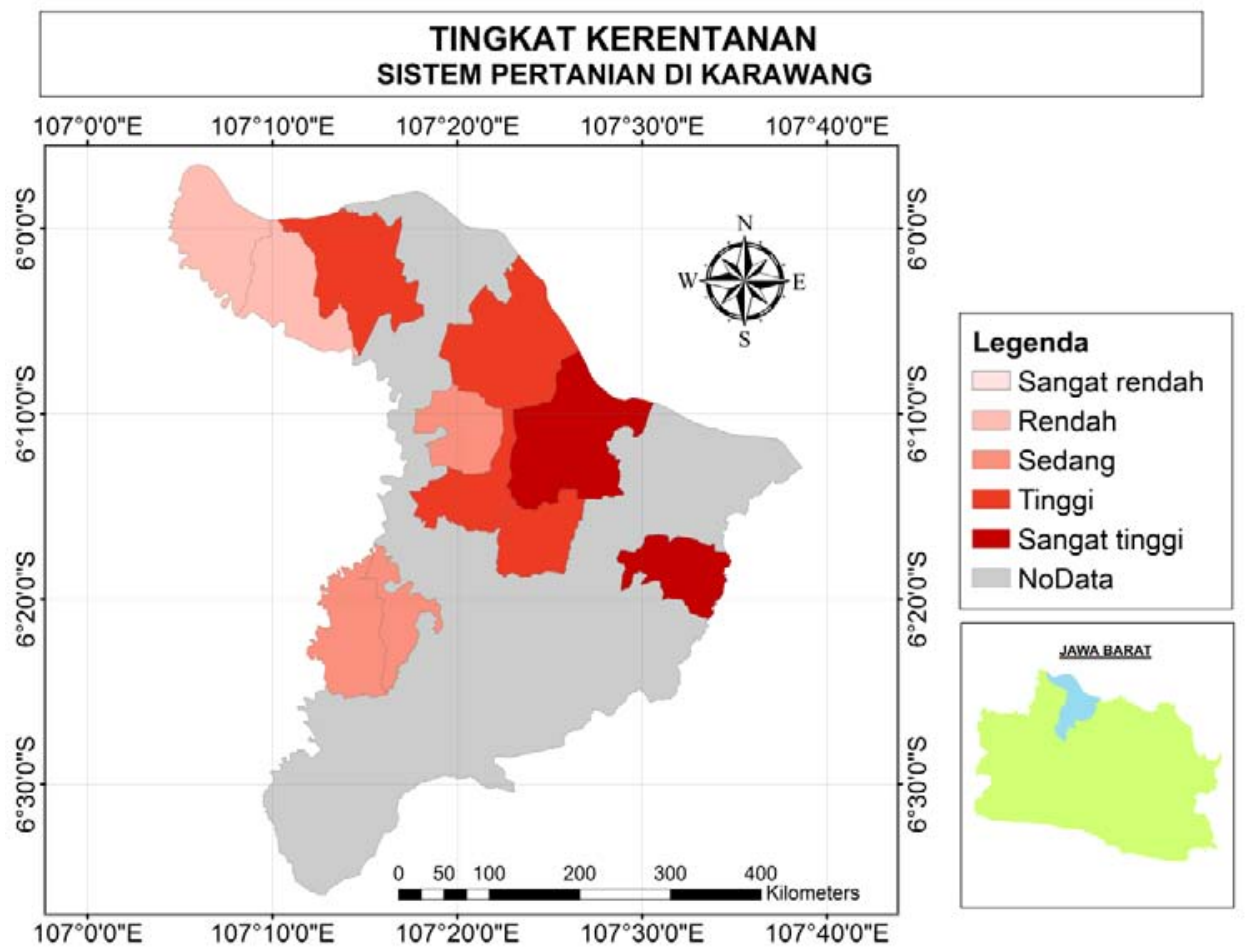

Figure 4: The level of vulnerability of agricultural systems in Karawang which is generally high

The level of risk are influenced by the magnitude of the hazard and vulnerability through relationship $\mathrm{HxV}$. Weights each exposure value is 0.308 ; sensitivity of 0.277 ; and adaptive capabilities of 0.415 . Weighting value of 0.533 hazard and vulnerability of 0.467 . These values are retrieved from the method of Pairwise comparison that is applied to this research. It appears in Figure 5 that the level of risk of agricultural system in Karawang most highly experienced by Tempuran, followed by sub Pedes and Banyusari.

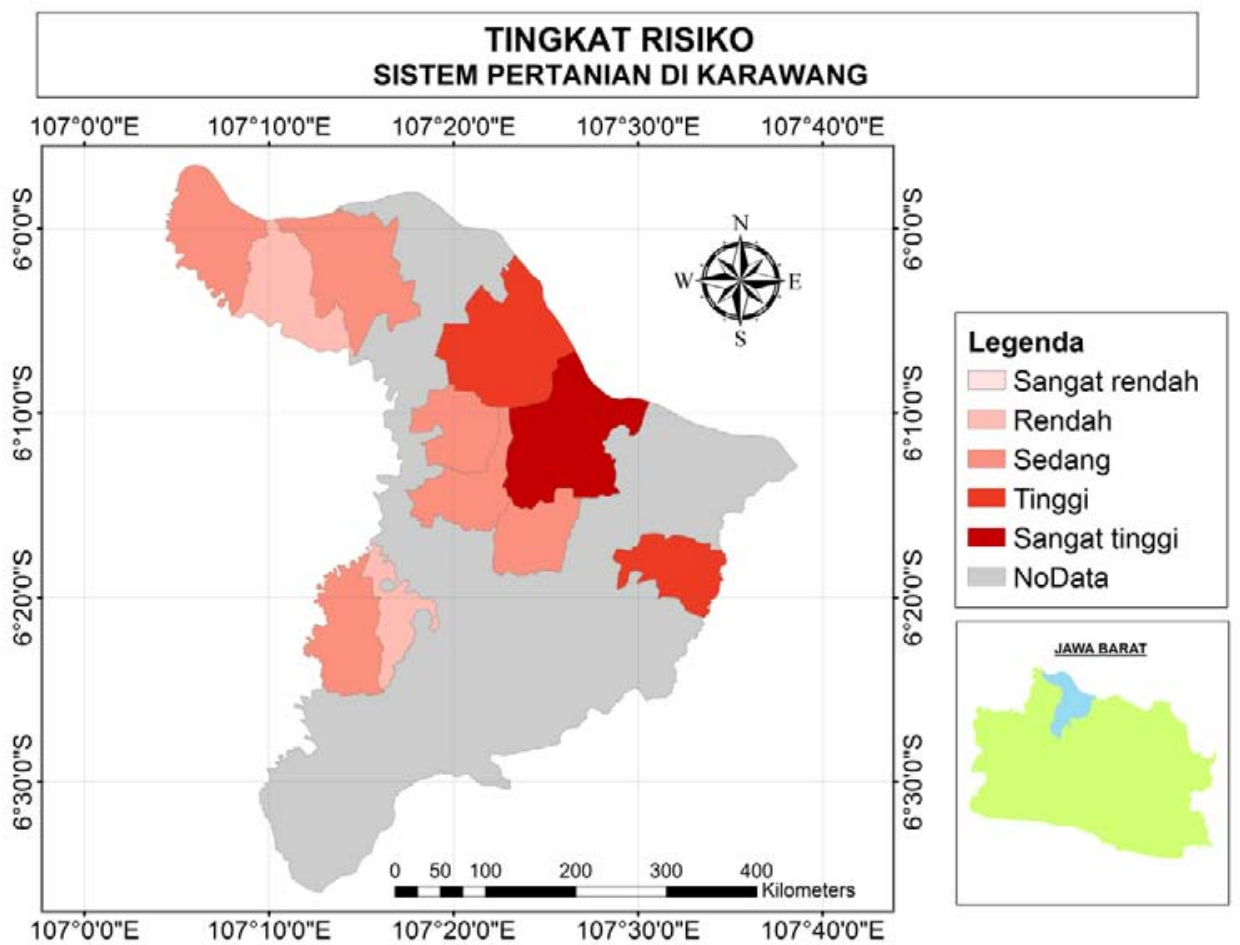

Figure 5: The level of risk of agricultural system in Karawang showed that Tempuran bordering the Java Sea is a subdistrict with the highest level of risk 


\section{Conclusions}

Projections of agricultural system in conditions of Karawang show that the level of hazard, vulnerability and risk is quite varied between eleven subdistricts are reviewed. Hazard level indicates that subdistrictTempuran and Pedes is the most high value whereas the level of vulnerability shows that Tempuran and Banyusari is very high which is shown by vulnerability index value close to 1 . The level of risk in agricultural systems against climate change will be experienced by the highest subdistrictTempuran. With the high level of risk that a number of mitigation must be done so that the impact can be reduced in addition to increasing the level of adaptation to society in the future.

\section{References}

[1] BPS, "Karawangdalamangka. BadanPusatStatistikKabupatenKarawang”,2014.

[2] IPCC, "Climate change 2014: Impacts, adaptation and vulnerability,"Summary for policymakers, IPCC WGIIAR5, 2014.

[3] J. Knox, T. Hess, A.Daccache, T.R. Wheeler,"Climate change impacts on crop productivity in Africa and South Asia," Environmental Research Letters, pp. 7-8, 2012.

[4] J. Lee, D. Nadolyick, V. Hartarska,"Impact of climate change on agricultural production in Asian countries: evidence from panel study," The Southern agricultural economic association annual meeting, Birmingham, England, 2012.

[5] M. Measy, "Indonesia: a vulnerability country in the face of climate change," Global Mayority E-journal, vol 1 no 1, 31-45, 2010.

[6] T.M.Osborne andT.R. Wheeler, "Evidence for a climate signal in trends of global crop yield variability over the past 50 years," Environmental Research Letters, pp. 8-9, 2013.

[7] Ruminta and Handoko, "Climate change risk and adaptation assessment South Sumatra," SectoralReportAgriculture, Ministry of Environment, Jakarta, Indonesia, 2012.

[8] B. Sultan, "Perspective: global warming threatens agricultural productivity in Africa and South Asia," Environmental Research Letters, pp.3-7, 2012.

[9] A.A. Yusufand F. Herminia, "Climate change vulnerability mapping for south east Asia," IDRC, CRDI, Sida, CIDA, EEP for Southeast Asia, 2009. 